\title{
Critical factors influencing the adoption of digital marketing devices by service-oriented micro-businesses in Nigeria: A thematic analysis approach
}

Sunday C. Eze (1) ${ }^{1,2 凶}$, Vera C. A. Chinedu-Eze ${ }^{3}$, Clinton K. Okike ${ }^{4}$ \& Adenike O. Bello ${ }^{2}$

This paper examines critical success factors shaping the adoption of digital marketing devices (DMD) by micro-businesses. The study adopted a qualitative approach. Both unstructured and semi-structured interviews were conducted with a total of 26 micro-businesses drawn purposefully from the online database and underpinned by technology, organisation and environment (TOE) framework. This helped to unravel 14 critical success factors influencing the adoption of DMD by micro-businesses in Nigeria. These factors include functional capability, adaptive capacity and expandability which are related to technology context. Collective understanding, degree of partnership and diversity of information are linked to the organisation context while the level of training, quality of service delivery, customer fulfilment and intense competition are associated with environmental context. The study expanded the TOE framework by unravelling the impact expectancy context which is associated with factors, such as budget, business expansion, diversity and return on investment. This study will be of importance to academics and practitioners because it provides further awareness into DMD adoption framework, factors critical to the DMD adoption and may assist in reducing the number of resources spent in search of information aimed at helping DMD adoption by micro-businesses.

\footnotetext{
${ }^{1}$ Department of Business Studies, Landmark University, Omuara, Nigeria. ${ }^{2}$ Department of Business Administration, Landmark University, Omu-Aran Kwara, Nigeria. ${ }^{3}$ Department of Agri-business, Michael Okpara University of Agriculture, Umudike, Nigeria. ${ }^{4}$ National College of Ireland, Dublin, Ireland. 凶email: sundayeze2010@gmail.com
} 


\section{Introduction}

dvances in digital marketing devices (DMD) such as emerging mobile digital applications for marketing provide a significant opportunity for small and medium scale enterprises (SMEs) to promote and advance their businesses. According to Scharl et al. (2005), digital marketing is a technology application that offers a business the opportunity to interconnect with clients regularly. This has transformed the ways both prospective and actual customers communicate through the use of phones and other devices (Hosseini et al., 2016; Arghya et al., 2020). These devices help businesses, whether small or large, to advertise their products via the internet and assist advertisers in contacting potential customers anytime and anywhere (Shankar and Balasubramanian, 2009; Madukua et al., 2016; Samoilenko and Osei-Bryson, 2018; Agostini and Nosella, 2020). Digital marketing is achieved when digital marketing planning and strategy development improve the company's digital marketing culture (Smutkupt et al., 2010; Arghya et al., 2020). According to Persaud and Azhar (2012), businesses should focus on policies and plans that focuses on stimulating emotional connection with their clients. SMEs that implement DMD into their essential marketing plans are required to focus on developing strategies that will create awareness, promote dialogue, and win the trust of the target customers. However, digital marketers experts have failed to establish such relationships because of the uncertainty of the usage and outcome (Eze et al., 2019).

Although digitalisation is not easy to integrate into SME's marketing strategies (Leppäniem et al., 2004; Wonglimpiyarat, 2015; Arghya et al., 2020) these applications provide avenues that enable organisations to share and interconnect with clients more efficiently (Shankar et al., 2010; Eze et al., 2014). The peculiar traits of digital marketing include personalisation capacity, making business transactions secured, smooth and easy communication between organisations and clients, hence, digital platforms allow businesses to fulfil their desired objectives which involve; access target audiences, interaction with target audience, customer's emotions and transactions. These platforms allow users to access them at any point in time and guarantees smooth interactions which give consumers the privilege to provide feedback by sending voice notes, texts among others. Eze et al. (2019) noted that because of the responsive nature of digital devices, businesses see these applications as part of their daily routine, which is instrumental to their success since online transactions are made available for their customers irrespective of distance and location. DMD is vital for micro and small businesses because it encourages customer patronage, creates awareness and promotes business growth and popularity (Franco and Garcia, 2018; Eze et al., 2019; Agostini and Nosella, 2020).

While DMD can help businesses personalise and make the business transactions secured between organisations and clients and allows access to target audiences, most research in this field has focused on using the traditional approach in examining DMD adoption. This approach considers technology adoption as a onedirectional approach and adopts mainly quantitative methods that hypothesised variable as constructs and predict the outcomes (Williams et al., 2009; Silva, 2007; Martin and Matley, 2001). It has been argued that most traditional approaches are not designed bearing SMEs in mind (see $\mathrm{Xu}$ et al., 2007; Eze and Chinedu-Eze, 2018a) because they are narrowly minded (Gilmore et al., 2007; Asongu and Le Roux, 2017). Similarly, Dwivedi et al. (2009) and Rantapuska and Ihanaine (2008) stressed that no single theory reasonably describes SME adoption behaviour because they often ignore some vital aspects of small business characteristics thus, studies should always consider broader and more robust frameworks when investigating issues relating to SMEs. Hence, it is believed that the TOE is a more robust framework to be the theoretical foundation (Alshamaila et al., 2013) for this study because it draw on a large number of factors that may shape the adoption of DMD in Nigeria microbusinesses.

Furthermore, many studies conducted in Nigeria extrapolated the findings of others in developed countries as if Nigeria operates in the same environment with those in advance countries and little has been studied on critical success factors shaping the adoption of DMD by micro-businesses in remote areas in Nigeria. Hence, the dearth of local scholarship that provides a clear direction to this kind of research in remote areas of Nigeria necessitated this study.

Also, regardless of the advancements of digital marketingrelated devices in SMEs in developed nations, the rate of adoption by SMEs in developing countries is relatively low (Okundaye et al., 2019; Napitupulu et al., 2018; Yunis et al., 2017; Hong et al., 2018). For example, in the US and the UK, SMEs contribute more than 90 per cent of employment and 50 per cent of the countries gross domestic product (GDP), while in developing countries like Nigeria, SMEs own over 90 per cent of the businesses in the country but contribute $<10$ per cent of the GDP (Gbandi and Amissah, 2014; Tobora, 2014; Okundaye et al., 2019), while 90 per cent of businesses in Ghana are SMEs and account for about 70 per cent of Ghana's GDP. The slow adoption rate of these devices in most African countries particularly in Nigeria has hindered the speed of economic development (Jones et al., 2014; Tob-Ogu et al., 2018; Okundaye et al., 2019; Rahayu and Day, 2017). Similarly, Okundaye et al. (2019) note that the rate of penetration of digital technologies between the developing countries and the western world is enormous. Western countries have a high internet penetration rate of 78.3 per cent compared to 32.4 per cent for developing nations, while the per cent of the household that own computer in a developing country is 27.6 per cent compared to 75.5 per cent in the western world (Okundaye et al., 2018). SMEs in developing countries have witnessed a slow and low adoption of digital devices compared to western world (Zafar and Mustafa, 2017; Okundaye et al., 2019), and the nature of this problem is becoming even more and more challenging for SMEs and require further investigations (Tob-Ogu et al., 2018). Therefore, this research remains relevant given that small businesses have limited knowledge of these new devices and any effort in understanding how these devices can be fully utilised would not only improve their understanding but make them proactive and strategic (Benamati and Lederer, 2001; Gutierrez et al., 2015; Samad et al., 2018; Agostini and Nosella, 2020; Hong et al., 2018) in taking decisions. This will also help reduce the number of resources and time spent in search of information that will aid

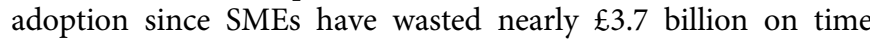
spent to search for relevant information using the internet as a tool (De Saulles, 2007) in the past. This paper, therefore, attempts to explore the critical success factors shaping SMEs adoption of DMD in Owerri West in Imo state, Nigeria in a bid to develop an integrated framework that may guide micro-businesses and help academics in exploring DMD adoption successfully in Nigeria.

\section{Literature review}

SMEs adoption of DMD. SMEs are the substratum for industrial growth (Ongori and Migiro, 2010; Lee, 2004; Parellada and Sorian, 2011; Mutula and Brakel, 2006; Gangwar et al., 2015; Agostini and Nosella, 2020) and disruptive technologies play a role in ensuring that they remain competitive in a highly volatile business environment. However, little studies have emphasised on digital marketing technologies by SMEs in Nigeria, particularly in Owerri West LGA of Imo State where substantial number of these 
businesses are SMEs. Studies that investigated issues about SMEs in Nigeria have always adopted approaches used by scholars in the developed world as if Nigeria operates the same culture with those in developed nations. This research focuses on microbusinesses in Nigeria because they are growing rapidly, representing 99 per cent of micro, small and medium enterprises (Kale, 2017 ) and contribute mainly to Nigeria national output (Eze and Chinedu-Eze, 2018). More specifically, the research centred on service micro-businesses because Nigerian economy is serviceoriented and the sector today is regarded as primary economic driver for digital marketing, and the substantial efforts to expand Nigerians economy is largely dependent on the service sector (Rantapuska and Ihanainen, 2008; Eze et al., 2019).

SMEs that utilise DMD in building their marketing strategies should concentrate mainly on developing plans that create awareness and interactions among their clients in a bid to winning the trust of target customers. However, most SMEs that use these applications have not been able to establish these interactions that aimed at shaping consumer's loyalty and purchase decisions. Scharl et al. (2005), note that DMD complement conventional marketing which is an uninterrupted flow of communication via digital applications such as smartphones. It is communication and or interaction with clients despite their locations (Smutkupt et al., 2010; Prause, 2019, Agostini and Nosella, 2020). DMD aid SMEs to bring their customers closer to their businesses via short message service (SMS) and mobile social management (Shankar and Balasubramanian, 2009). Therefore, for SMEs to strive, they need to develop a structure where DMD plays an essential role in general marketing. These applications have metamorphosed into new methods for businesses be it large or small to share and relate with the target market in a well-organised and effective manner (Jones et al., 2014). Also, with the emergence of DMD marketing has gradually moved towards automation. Marketing has moved from a strategy of concentrating on a small person who uses a product or service to a stage of adopting a single marketing success plan to draw the attention of the entire market which has bought a better way of building effective promotional strategies. (Amirkhanpour et al., 2014; Prause, 2019). SMEs who possess the requirements to establish a DMD culture are likely to engage more with mobile marketing (Hong et al., 2011; Smutkupt et al., 2010). With the use of DMD a small business manager can access its clients even quicker, unlike the conventional marketing strategies (Hopkins and Turner, 2012; Agostini and Nosella, 2020). Hence, knowing what customers' needs and wants using DMD is vital for the marketer to be productive (Persaud and Azhar, 2012).
Technology-organisation-environment framework. The study was underpinned by technology, organisation and environment (TOE) framework. Designed by Tornatzkyand Fleischer (1990), and emerged from psychology. The TOE is a conceptual framework used by organisations to examine what IT applications are more likely to improve their services by accepting and implementing such technological inventions, which are shaped by either technological, organisational, and the environmental (DePietro et al., 1990). The technological dimension covers but not limited to the internal and external expertises that play significant roles in the organisation. This also extends to tools as well as procedures. The organisational dimension looks at the structures, resources, as well as the size of the business and degree of monopolisation. The environmental dimensions focus on the size of the business, competitors, macroeconomic perspective, and the regulatory background (DePietro et al., 1990; Eze et al., 2018; PR Newswire, 2019; Lian et al., 2014; Maclennan and Van Belle, 2014). According to Alshamaila et al. (2013) and Tornatzky and Fleischer (1990), these three dimensions provides both limitations and opportunities for the advancement of technological innovation and shape the manner to which micro-businesses implement new technology. Also, Eze et al. (2019) argued the TOE framework is a very important analytical tool that unravels both the drivers and inherent features of innovation, proficiencies and other environmental circumstances of the adoption organisations. Besides, many studies (see Eze and Chinedu-Eze, 2018b; Maclennan and Van Belle, 2014; Ruivo et al., 2014; Nuryyev et al. 2020) have used the TOE framework. These studies have shown empirical resilience in the explanation of technology adoption in firms (Madukua et al., 2016).

Justification for using the TOE framework. The researchers specifically adopted the TOE framework because the TOE framework incorporates environmental dimensions which were ignored by the Rogers Innovation diffusion theory (IDT). The framework has been able to explain intra-firms innovation adoption better (Oliveira and Martins, 2011; Madukua et al., 2016). Besides, it is believed that the TOE is much more a robust framework to be the theoretical bases (Alshamaila et al., 2013) for this study and can draw on a large number of factors that may shape the adoption of DMD in Nigeria micro-businesses, providing very significant analytical scope of DMD adoption (Oliveira and Martins, 2011). Figure 1 presents the analyiical framework of the study.

Methodology. Today, information system (IS) research is no longer focused on technology alone but has accommodated both the organisation and management dimension (Myers, 1997;

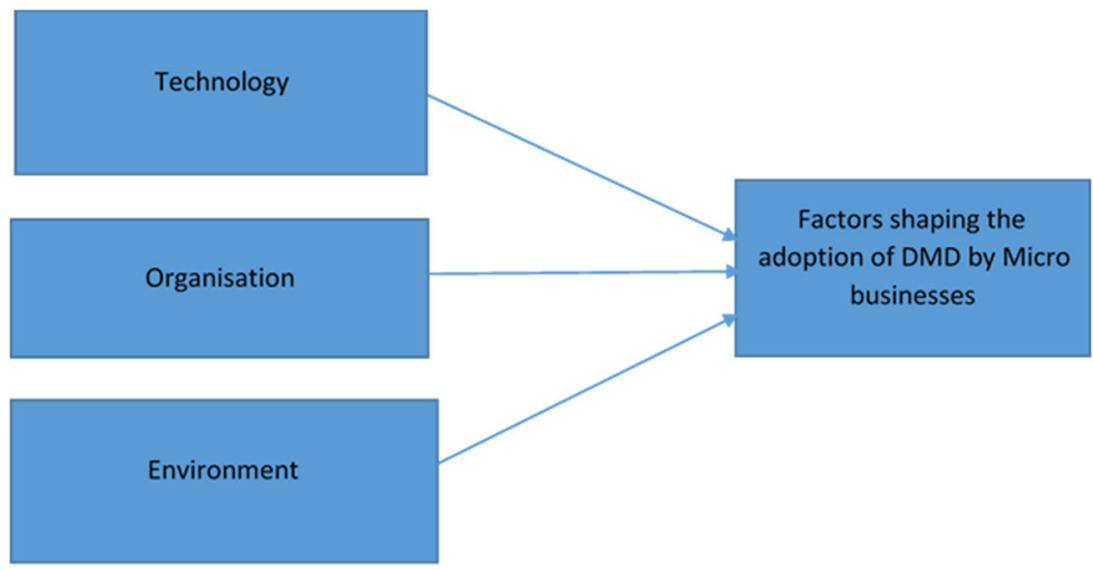

Fig. 1 Proposed study framework. 
Benbasat et al., 1987). Studies have challenged technology adoption researchers because of how they constantly overemphasised on the confirmatory statistical techniques (Silva, 2007; Schwarz and Chin, 2007). According to Silva (2007), researchers that often deploy quantitative approach most times are not disputable, and when there are issues on the approaches or theories used, these issues are linked to either the instruments adopted or the sample size. Research on IT adoption needs both methods and explanatory theories, that can assist in discovering issues understudy in a more comprehensive manner (Silva, 2007). Qualitative approaches are alternative method and also provide rich and comprehensive results (Lee, 2003; Elliot and Loebbecke, 2000).

This study, therefore, adopted qualitative approach in order to explore the critical factors influencing the adoption of DMD by micro-businesses in Nigeria: In a bid to achieve this, the study first reviewed extant literature to avoid having constraints on views about the research area, to ascertain if the code(s) identified are linked to the TOE framework and if these codes can be applied successfully to the raw data at the initial stage of unstructured interviews. The purpose of this is to ascertain if the codes are credible. Furthermore, to carry out semi-structured interviews which will help develop themes and validate the outcomes.

Purposive sampling was used because the study was aimed at discovering the small business manager's real-life experiences. The study, therefore, selected units of analysis (SMEs) at a single level aimed to help make the evaluation grounded on the objectives of the study instead of generalising it statistically (Mason, 1996). SME managers were selected and drawn from service-oriented industries in Owerri-west, Imo State, Nigeria. These sets of managers have adopted one form of DMD or the other in the last 3 years. For this research, micro-businesses are defined as businesses that have employed 1-10 workers.

The choice of selecting Owerri, the state capital city of Imo state was because the state has about 1.3 million registered microbusinesses and generate employment of about 858,003 (2.48 per cent) persons for male and 602,331 (2.67 per cent) female however, the rate at which these businesses adopt DMD are low (Small and Medium Enterprise Development of Nigeria and National Bureau of Statistics collaborative Survey, 2013). Most micro-businesses in Owerri do not have any strategic plan, guide or framework that aid the adoption and usage of these devices regularly despite the number of small businesses in this area.

Recently, the report released by the National Bureau of Statistics (2019) revealed that three south-western states: Lagos (11.5\%), Oyo (8.4\%) and Osun (4.1\%) in Nigeria have the highest number of SMEs in Nigeria while the best performing areas include Kwara (526.5\%), Nasarawa (132.5\%) and jigawa (116\%). However, Owerri, Imo State was never listed among the best performing states. This implies that SMEs in Owerri, Imo State is way back in performance hence the perception towards this backslide is because of their inability to adopt efficient and effective DMDs to fit into the current trend in the marketing system. This explains why most small business only uses such platforms to send mails and acquire information (De Haan et al., 2018) only. The aim of this study is to bridge the gap by developing an integrated framework that will guide future studies on DMD adoption in SMEs and help SMEs improve the adoption rate in this area.

The population of this study consists of managers and employees of selected micro-businesses in Owerri West Local Government Area of Imo State, Nigeria. One hundred participants were selected from the Imo Business Directories and 26 out of the 100 agreed to be interviewed (see Table 1).

Interview. Both unstructured and semi-structured interviews were carried out. In details, the unstructured interviews were

\begin{tabular}{|c|c|c|c|}
\hline Participants & Role & Company size & Sector \\
\hline M1 & Manager & 10 & Security services \\
\hline M2 & Manager & 8 & IT software development \\
\hline M3 & Manager & 7 & Telecommunication \\
\hline M4 & Manager & 2 & Telecommunication \\
\hline
\end{tabular}

carried out first with 4 (M1-M4) participants to critically look at the research topic in a bid to ascertain the present state of DMD adoption by SMEs, apply samples of raw data to the the thoeritical codes (technology-organisation-environment) generated to ascertain their applicability to the subsequent raw data. This assisted in developing the semi-structured interview questions used at the last stage of the data collection exercise. This helped in grasping the richness of the participant's views (Oates, 2006) about the DMD adoption. Before the commencement of the interview, the researchers sent formal letters containing the purpose of the interview as well as confidentiality of information from the interviewee. This process was to ensure that participants goes through them and feel more comfortable before the interview and to help them ascertain the researchers' credibility (Oates, 2006), which is an integral part of the interview protocol since relying upon peoples memory may lead to bias and error. The interviews lasted for $1 \mathrm{~h}, 30 \mathrm{~min}$ each. Specifically, four unstructured interviews (preliminary study) were conducted while semi-structured interviews were carried out with 22 (M5-M26) participants. The study was carried out within Febuary-December 2019.

Tables 1 and 2 show the company profiles which included the participant profile for the preliminary study and the main study participants.

It is important to note that the study adopted a qualitative approach which is without its limitation to this study. This limitation extended to research design, rigour in the collection of data and the management of the large volume of the raw data, as well as the way the data was analysed and the credibility of the findings. This may result in unanticipated respondent-andresearch bias in the data analysis (Macredie and Mijinyawa, 2011). This may hamper alternatives and insights into the factors shaping DMD. Therefore, we encourage other researchers to deploy an alternative research approach such as mix- method and case study to further validate the findings.

\section{Data analysis}

The study adopted a thematic data analysis. First, theory-driven thematic analysis was adopted to analyse the data because the codes adopted in this study was drawn from TOE framework while others were empirically driven. This aid in unveiling the characteristics of the codes in more straightforward terms (see Table 2) based on the name, definition and description of the codes (Miles and Huberman, 1994). This often helps to check the credibility and dependability of the data analysis process. Figure 2 illustrates the process involved in the data analysis process. Stage one to stage three were deployed during the preliminary investigation where the initial raw data drawn from the unstructured interview were analysed. At the next stage, all the data drawn from both the unstructured and semi-structured interview were imported into NVivo (see stage 4 of Fig. 2) for analysis because of the massive data involved. NVivo is a software used in the analysis of qualitative data. This assisted in the management of data quickly. Table 3 also shows the guide on how the raw data were 


\begin{tabular}{|c|c|c|c|}
\hline Participants & Role & Company size & Sector \\
\hline M5 & Director & 10 & Software development \\
\hline M6 & Manager & 9 & Training \\
\hline M7 & Manager & 5 & Security \\
\hline M8 & CEO & 6 & Finance \\
\hline M9 & Manager & 9 & Fiance \\
\hline M10 & Owner & 9 & Property \\
\hline M11 & Owner & 5 & Telecommunication \\
\hline M12 & IT Director & 6 & Consultant \\
\hline M13 & Director & 10 & Internet marketing \\
\hline M14 & Manager & 10 & Property management \\
\hline M15 & Manager & 9 & Consultant \\
\hline M16 & Owner & 5 & Money management \\
\hline M17 & Owner & 1 & Internet marketing \\
\hline M18 & $\begin{array}{l}\text { Business } \\
\text { Analyst } \\
\text { Manager }\end{array}$ & 4 & Finance \\
\hline M19 & $\begin{array}{l}\text { Operational } \\
\text { Manager }\end{array}$ & 5 & Security training \\
\hline M20 & IT Manager & 10 & IT consultant \\
\hline M21 & Owner & 6 & Property \\
\hline M22 & Director & 8 & Property \\
\hline M23 & Manager & 10 & Consultancy \\
\hline M24 & Manger & 5 & Consultancy \\
\hline M25 & Manager & 7 & Financial firm \\
\hline M26 & Manager & 8 & Digital marketing \\
\hline
\end{tabular}

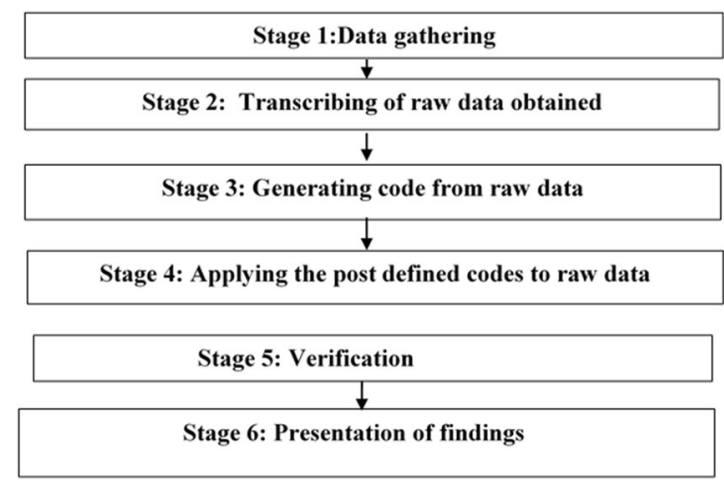

Fig. 2 Data analysis process.

coded. Furthermore, a guide was designed during the analysis concerning the description of the codes which aided the coding the data (see Table 4) and interpretation of data (see Boyatzis, 1998). It has been argued that the practical definition of factor associated with theoretical concepts has become challenging in the analysis and validation process. Hence, both theoretical and empirical variables associated with these factors can be deployed to develop a hypothesis (Macredie and Mijinyawa, 2011) and scholars should further conduct a cross-sectional comparative study to understand better factors shaping DMD adoption.

To validate the findings, inter-coder reliability analysis was carried out using both the quotes and categories drawn from the raw data (Bryman, 2008) with two judges. These judges reviewed and compared the codes with the themes that emerged. The finding of the analysis showed $82 \%$ agreement relating to the study scope. This is more than $70 \%$ benchmark recommended by Miles and Huberman (1994). Figure 2 above was a step by step method used which indicate how the raw data was reported (dependability check) as well as the conformability checks to that ensures that data is linked to the interpretation (see Boyatzis, 1998; Macredie and Mijinyawa, 2011).

Although the researchers were confident in the data analysis and the findings using thematic analysis, other factors (accessability, technical know how, efficiency driven, owner's support) were identified but were not included in the research because few participants supported these factors. And failed to pass reliability test. Therefore, further studies should explore other factors in both service sectors and other industries using different approaches.

\section{Findings and discussion}

Tables 5-9 show themes relating to each code, their supporting cases and supporting evidence. The factors (themes) created were gathered based on the features of the theoretical codes drawn from the TOE framework. These factors were shown in Tables 5-9. This process unveiled the critical success factors shaping the adoption of DMD in micro-businesses in the study area.

Framework on critical success factors influencing the adoption of DMD by microbusinesses. The conceptual framework in Fig. 3 developed in this study shows critical factors influencing the adoption of DMD. These factors depicted in the framework were based on the classification of theoretical codes-TOE and one empirical code-Impact expectancy, which emerged inductively in the cause of the analysis. Both the exploratory and the explanatory features of the framework and the critical success factors depicted in the framework are dependent on the respondents narratives, theoretical and empirical codes as well as the literature which aid in the explanation of the factors shaping the DMD adoption by micro-businesses. While the developed framework can serve as a frame of references (Agarwal, 2000; Macredie and Mijinyawa, 2011) in understanding the factors shaping DMD adoption, operational meanings of the codes and the identified factors may also be used as an analytical instrument for researchers to understand and explain factors influencing DMD adoption in the future.

DMD may assist SMEs to develop business ideas and create partnerships that would enhance the value-chain through inter and intra-organisation information sharing which aid collaborative environments (Raymond and Bergeron, 2008; Dubé et al., 2017). This leads to advanced levels of product and process innovation (Economides and Jeziorski, 2017) which may lead to competitiveness (Ciechanowski et al., 2019) and reduce cost due to disintermediation (Kannabiran and Dharmalingam, 2012; Alba et al., 2005; Economides and Jeziorski, 2017) inventory holding, total cycle-time (Ukoha et al., 2011), virtual stores, communications, and network, lead-time compression, and transparency in improving customer service (Yesbank, 2009). However, one of the surprising findings is the impact expectancy dimensions which is incorporated in the framework and assist in the extended TOE framework. The finding revealed that although most SMEs may have the capacity to exploit opportunities associated with DMD compared to large organisations considering their limited human and financial resources, and the mode of operations which support fast decision making (Ciechanowski et al., 2019), most SMEs are not always passionate in trying and adopting new solutions. The reason being that such devices must demonstrate an immediate and significant positive impact on their businesses. The finding emerged because most SMEs are moved to trying new solution especially when such application helps in reduction of costs, business growth, regular return on investment and creates unique services that may differentiate them from others since over $2 / 3$ of IT applications still fail in most businesses (Barrat et al., 2006). This finding is significant to this study 


\section{Table 3 Guide for a description of codes.}

Technology

Organisation

Environment

Impact expectancy
Technology context refers to both the internal and the external factors that influence SMEs adoption of DMDs Organisation context refers to those resources that shape the adoption of DMD by micro-businesses Environmental context refers to both the internal and external factors impact organisations adoption of DMDs Impact expectancy refers to anticipated benefits due to the adoption of DMDs

\begin{tabular}{|lcll|}
\hline \multicolumn{2}{|l|}{ Table 4 Reliability analysis. } & & \\
Areas & $\begin{array}{l}\text { Number } \\
\text { of judges }\end{array}$ & Reliability & \\
\cline { 2 - 4 } & 2 & First judge & Second judge \\
\hline $\begin{array}{l}\text { Factors shaping the } \\
\text { adoption DMD by } \\
\text { microbusinesses }\end{array}$ & & $0.87(87 \%)$ & $0.82(82 \%)$ \\
\end{tabular}

because SMEs are likely to be more proactive and strategic in dealing with issues like this in the future when the need arises. The critical success factors are now discussed below under technology, organisation, environment and impact expectancy dimensions.

\section{Technology}

Functional capability. Operational efficiency is the extent to which the DMD help meet the overall needs of the firm. From the analysis, micro-businesses face pressure to become commercially viable and sustainable. However, because of the economic hardship, the DMD adoption may even be much more difficult though these applications may be relatively cheap (Okundaye et al., 2019). While several micro-businesses have engaged in DMD adoption, it was noted that DMD would be of utmost value if it is of high performance, efficient and accomplishes much without complexity.

"[-] Is the IT devices efficient? Does it provides similar services in the large organisation provide" (M5).

"The DMD must prove to move the company to a higher level” (M2).

"[-] Can the DMD aid in operational efficiency and provide some of the benefits large organisations benefit from?" (M7).

In support of the above points, several interviewees [M1], [M11], [M14], and [M15] raised a similar point. Aboelmaged (2010), Li et al. (2011), and Madukua et al. (2016) in their studies further supported the findings. Also, studies have argued that new applications that appear to be complicated and slow business activities will hinder its widespread (Ritchies and Brindley, 2005; Teo et al., 2011; Ramayah et al., 2016; Brown and Lockett, 2004; Teo and Pan, 2008; Yunis et al., 2017; Gbadegeshin et al., 2019; Nuryyev et al., 2020).

Adaptive capability. Adaptive capability is the extent DMD integrate into both the current business processes and the existing technology in the business. According to Zhu et al. (2003), connectivity reduces inconsistency and can as well restrict compatibility if the technology is challenging to integrate with the current technology arrangement. According to participants (e.g. M1, M2, M10, and M14), small businesses need to identify opportunities DMD offer before adopting them. This requires gathering adequate information to learn how to overcome failure. Some participants echoed this and supported by others:
"Can the DMD modelled in a manner that it can work with what we have in the organisation? Is it much easier to integrate?" (M3).

To what extent does the DMD interface with the existing application we have?" (M13).

The finding is in line with Khoumbati et al. (2006) that argued that the failure to integrate existing infrastructure with the new ones might be expensive, and organisations should avoid this from the onset (Aduwa-Ogiebaen and Iyamu, 2005; Napitupulu et al., 2018). According to Fitzgerald and Kenny (2003), this occurs when the characteristics of the new technology are incapable of fitting into the existing organisational norms.

Expandability. Expendability is the capacity of the DMD to adapt to either the new old business processes frequently (Eze et al., 2019). Observations revealed that the flexible nature and the ability of the DMD to continually intertwine with the new features is the starting point for other business processes to be achieved. Some participants noted that the expandability of the DMD aid the processes of innovation and business process and moderates the cost of developing or adopting entirely new technology. Although some micro-businesses during the analysis noted that advances in technology have made some DMDs expandable, some are still not. The finding reveals that majority of microbusinesses would be out to adopt DMD where the applications could easily be integrated with others. This was highlighted:

"I think in our organisation, it will get to a point we can decide to replicate or make the application bigger". Can the capacity be expanded shortly? (M12).

"Our business will adopt applications that will take over or existing house applications we have? That will shape our decision toward acquiring new product” (M14).

Similar studies (e.g. Gilmore et al., 2007; Fitzgerald and Kenny, 2003; Gholami et al., 2009; Wamba and Carter, 2014; Yunis et al., 2017; TAL, 2018; Gbadegeshin et al., 2019) findings have noted that flexible IT applications often adapt to an existing organisational arrangement which often leads to trial. This was further supported by M2, M3, M4, M12, M19, and M20.

\section{Organisation}

Collective understanding. Collective understanding is the understanding of the business purpose among various persons in the organisation through open interaction. Although the perception of small business managers on DMD might differ based on the knowledge and social setting, small business managers must acquire and distribute technical information that every person must understand some meaning to all both within and outside the organisation which are understood by all. This was highlights across cases:

"We often come together to evaluate what the new technology can bring to the table, which leads to our decision to adopt or not to adopt" (M19). 
Table 5 Technology factors and supported cases.

Factors (themes)

Technology

Functional capability

Adaptive capacity

Expandability

Cumulative
Related cases

$M 1^{\star \star \star}, M 2^{\star \star}, M 5^{\star \star \star \star}, M 7^{\star \star \star}, M 9^{\star \star}, M 11^{\star \star}, M 14^{\star \star \star}, M 15^{\star \star}$

$M 1^{\star \star}, M 2^{\star}, M 3^{\star \star}, M 10^{\star \star \star}, M 13^{\star}, M 14^{\star \star \star}, M 16^{\star}, M, 17^{\star}, M 20^{\star \star}$

$M 2^{\star \star}, M 3^{\star \star}, M 4^{\star}, M 12^{\star \star}, M 14^{\star \star}, M 18^{\star \star \star}, M 19^{\star \star}, M 20^{\star \star \star}$

M1, M2, M3, M4, M5, M7, M9, M10, M11, M12, M13, M14, M16, M18, M19, M20
No. of cases coded

8

$16 / 26(61 \%)$

M1, M2 represents the Interviewees, while "*" represent the number of references on text.

\section{Table 6 Organisational factors and supported cases.}

\section{Factors (themes)}

Related cases

Organisation

Collective understanding

Degree of partnership

Diversity in information

Cumulative
$M 1^{\star \star}, M 5^{\star \star}, M 7^{\star \star}, M 8^{\star \star} 8, M 15^{\star}, M 19^{\star} 8, M 22^{\star \star \star}, M 23^{\star \star}, M 24^{\star \star}, M 26^{\star \star \star \star}$

$M 1^{\star \star \star}, M 2^{\star}, M 3^{\star \star}, M 4^{\star \star}, M 5^{\star}, M 12^{\star \star \star}, M 15^{\star \star}, M 22^{\star \star}, M 23^{\star \star \star}$

$M 5^{\star}, M 6^{\star \star}, M 7^{\star \star}, M 11^{\star} 8, M 12^{\star \star}, M 16^{\star \star \star}, M 17^{\star \star}, M 19^{\star \star \star}, M 13^{\star \star}, M 15^{\star \star}$

M1, M2, M3, M4, M5, M7, M8, M11, M12, M15, M17, M19, M22, M23, M24, M26
No. of cases coded

10

10

$16 / 26(61 \%)$

M1, M2 represent the Interviewees, while "*" represent the number of references on text.

Table 7 Environment factors and supported cases.

\section{Factors (themes) Related cases}

Environment

Level of training

Quality of service

delivery

Customer Ffulfilment

Intense competition

Cumulative
$M 1^{\star \star}, M 2^{\star \star}, M 5^{\star \star}, M 9^{\star}, M 11^{\star \star}, M 13^{\star \star \star}, M 14^{\star \star \star}, M 17^{\star \star \star}, M 18^{\star \star \star}, M 20^{\star}$

$M 2^{\star \star}, M 3^{\star \star}, M 7^{\star \star \star}, M 10^{\star} 8, M 11^{\star} 8, M 9^{\star \star}, M 12^{\star}, M 15^{\star \star \star}$

$M 1^{\star}, M 4^{\star \star}, M 5^{\star \star \star}, M 6^{\star \star \star}, M 7^{\star \star \star}, M 10^{\star \star \star}, M 12^{\star \star}, M 14^{\star \star \star}$

$M 1^{\star \star \star}, M 5^{\star \star \star}, M 9^{\star \star \star}, M 13^{\star \star \star \star}, M 14^{\star \star}, M 16^{\star}, M 23^{\star}, M 25^{\star \star}, M 26^{\star \star \star}$

M1, M2, M3, M4, M5, M6, M7, M8, M9, M10, M11, M12, M13, A14, M16, M17, M18, M23, M23,

M25, M26
No. of

cases coded

M1, M2 represent the interviewees, while "*» represent the number of references on text.

\section{Table 8 Impact of expectancy factors and supported cases.}

\section{Factors (themes)}

Impact expectancy

Budget

Business expansion

Diversity

Return on investment

Cumulative
Related cases

$M 1^{\star \star \star}, M 2^{\star \star} M 3^{\star}, M 5^{\star \star \star \star}, M 6^{\star \star \star \star}, M 9^{\star \star}, M 11^{\star \star \star \star}, M 15^{\star \star \star}, M 16^{\star \star \star}, M 20^{\star \star \star}, M 2^{\star \star}$

$M 5^{\star \star \star}, M 6^{\star \star}, M 9^{\star \star \star}, M 14^{\star \star}, M 20^{\star \star}$

$M 5^{\star \star \star \star \star \star \star \star ~}, M 13^{\star \star \star}, M 16^{\star \star \star}, M 17^{\star \star}, M 20^{\star \star}$

$\mathrm{M}^{\star}, \mathrm{M}^{\star \star \star}, \mathrm{M} 9^{\star \star}, \mathrm{M} 12^{\star \star \star}, \mathrm{M} 13^{\star \star \star}, \mathrm{M} 14^{\star \star \star}, \mathrm{M} 20^{\star \star}, \mathrm{M} 23^{\star \star}$

M1, M2, M3, M5, M6, M9, M11, M12, M13, M14, M15, M16, M17, M20, M23

No. of cases coded

M1, M2 represent the interviewees, while "*" represent the number of references on text.

I do not take the decision alone. It requires a collective effort of everybody both within and outside the organisation (M23)

Nelson and Cooprider (1996) note that knowledge that is shared among various units of the organisations help in the improvement of both the performance and operational efficiency and bring about IT understanding (Reich and Benbasat, 2000; Tobora, 2014). This finding implies that shared meaning is essential in every organisation, and how the information is circulated impacts technology adoption (Armstrong and Sambamurthy, 1991; Gbanidi and Amissah, 2014; Tob-Ogu et al., 2018; Gbadegeshin et al., 2019).

Degree of partnership. Because of the competitive advantages enjoyed by organisations, most organisations tend to partner extensively. A partnership is the commitment of various actors in a harmonised manner to solve a problem. Working Collaboratively aid IT adoption decision. From the analysis, the 


\section{Table 9 critical success factors influencing the adoption of DMD by microbusinesses.}

\section{Factors shaping DMD Samples of supporting evidence}

adoption

Code 1: Technology:

Functional capability

Adaptive capacity

Expandability

Code 2: Organisation Collective understanding

Degree of partnership

Diversity of information

Code 3: Environment Level of training

Quality service delivery

Customer fulfilment

Intense competition

Code 4: Impact expectancy Budget

Business expansion

Diversity

Return on investment
"[-] Is the IT devices efficient? Does it provides similar services large organisation provide" (M5)"The DMD mustprove to moves the company to a higher level" (M2)

"Can the DMD modelled in a manner that it can work with what we have in the organisation? Is it much easier to integrate?" (M3)

"To what extent does the DMD interface with the existing application we have?" (M13).

"I think in our organisation, it will get to a point we can decide to replicate or make the application bigger". Can the capacity be expanded shortly? (M12)

"Our business will adopt applications that will take over or existing house applications we have? That will shape our decision toward acquiring new product" (M14)

"We often come together to evaluate what the new technology can bring to the table, which leads to our decision to adopt or not to adopt" (M19)

I do not take decisions alone. It requires a collective effort of everybody both within and outside the organisation (M23)[-] (M23)

"Most often a substantial number of small businesses do not like collaborating with others". [-] partnering with others concerning digital marketing devices to adopt especially SMEs within the same line of business is often helpful even with competition" (M12)

"I must tell you that every member of the organisation played a role to ensure that we get a technology that our customers will appreciate" (M15)

"[-] I must let you know that in most cases I am the innovators driving the technology including the IT people and those that develop them to ensure that the technology is modelled in line with our needs application is in line with our need. I may not do it alone" (M9)

"[-] we often bring our expertise together and regular reviewing review the outcome. External advice becomes important at this point" (M12)

"Although we are a small company, we often train. This may depend on the time (M11)" How much time is required to get usedto the technology? If it takes too much time to learn it, we may not adopt it (M2)

"[-] is the technology going to be fast at all times? [-] for me as a manager, speed and consistency is a determinant factor (M15)

The DMD must be one capable of improving our process and delivery" (M12)

"Our customers are the reasons why we are still in business customers. Therefore, the DMD must be capable of satisfying the needs and desires of our customer" (M11).

"DMD is a means to an end as such; we must regard it as one of the capabilities to be able to relate with our customers and meet their needs[-]" M12

"Because we are small and we want to remain in business, we must compete by getting an application that can help up fight competition" (M5)

"Because of the intense competition going on, I was concerned that we might be left behind" (M1).

"For us to be competitive, we just have to keep adopting new DMD" (M9)

"At the moment we are small. If it is relatively cheap and can accommodate our budget we are good to try it" (M1)

"[--] Budget is one of the critical success factors we consider [-]. Can the application help reduce our budget in terms of cost and workforce? (M15)

"Our motivates to look for new DMDs is growth. How regular can the technology assist in increasing our customer base?" (M14)

"Can we acquire 45 clients or more in less than three months? That alone will be a deciding factor" (M5).

"for us to decide on that will depend largely on cost reduction of the application as well as assisting us in creating a niche in the market" (M5)

The DMDs should be able to differentiate us from our rivalry? (M13) by helping us to create something new at all times. "[-] We would always consider DMDs that can help us maximise profit" (M20)

"If we invest \#30,000, as long as it yields a return of \#15,000 we will adopt it" (M23) majority of micro-businesses do not collaborate even when this strategy assists organisations to understand their partners. The finding reveals that most managers do not partner because they feel that they might be exposing their ideas to their rivalry, hence their competitive edge is not exposed. However, it was observed by participants that such collaboration is becoming beneficial:

"Most often a substantial number of small businesses do not like collaborating with others"(M15). "[-]when we partner with others concerning digital marketing devices it is often helpful even with competition" (M12).

"I must tell you that every member of the organisation played a role to ensure that we get a technology that our customers will appreciate" (M15).
The implication of the finding is that DMD facilitates and enable relationships to be established among workgroups for better adoption decision to be made. This was further mentioned by other participants (A15, A22] and A23). This finding was consistent with previous studies (Gholami et al., 2009; Zafar and Mustafa, 2017; Rahayu and Day, 2017; Gbadegeshin et al., 2019).

Diversity of information. The continuous need for technology devices has made most organisations' information intensive. Firms no longer rely on information with the organisation but also embraced such from both within and outside the firm. This often creates a new knowledge of the IT to adopt. Tenkasi and Boland (1995), note that information helps in the learning process and it ensures that the complexity related to any new application is understood. This was highlighted: 


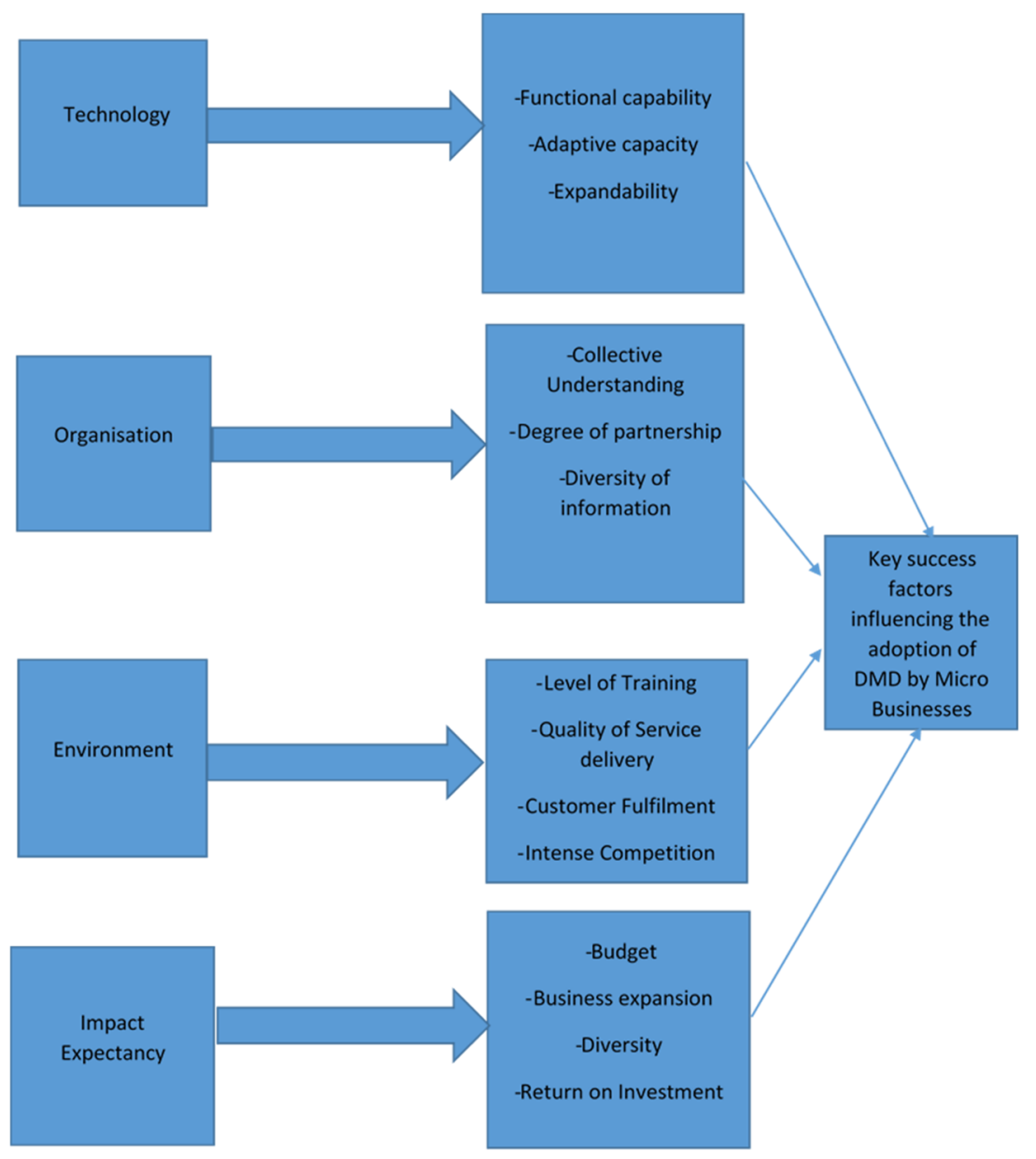

Fig. 3 Framework on crucial success factors influencing the adoption of DMD by microbusinesses.

"[-] I must let you know that in most cases I am the innovators driving the technology including the IT people and those that develop them to ensure that the technology is modelled in line with our needs application is in line with our need. I may not do it alone." (M9)

"[-] we often bring our expertise together and regular reviewing review the outcome. External advice becomes important at this point." (M12).

These findings were consistent with other participants (A6, A13, A15) and supported by previous studies (see McGrath and Maiye, 2010; Zafar and Mustafa, 2017; Eze et al., 2018). The finding implies the adoption success of DMD will often depend on how active micro-business managers can build their capabilities, integrate and exchange information with other employees and the external context.

\section{Environment}

Level of training. DMD evolve continuously such that they can become obsolete so quickly. The analysis revealed that the majority of micro-businesses go for training to learn how best to improve in the implication of new technology and to assess what is now. The training helps small business managers and the workers to learn how the new applications can contribute to their organisational growth. However, the finding reveals that if the training takes time, such application may be ignored. This was pointed out across cases:
"Although we are a small company, we often train. This may depend on the time" (M11).

"How much time is required to get used to the technology? If it takes too much time to learn it, we may not adopt it” (M2).

"When an item is introduced it is not always easy at the initial stage [-]. It required that we will study it first" (M9).

According to Rantapuska and Ihanainen (2008) most managers found it difficult to wait and learn about the new technology because they feel that it will be time-consuming. This attitude hinders them to acquire the right knowledge for effective decision to be made instead they automate the existing ones (Eze and Chinedu-Eze, 2018a, 2018b; Rahayu and Day, 2017)

Quality service delivery. Quality service delivery is the capacity of the DMD to improve service delivery manner, the company's processes and profit in an efficient manner. SMEs interviewed thought that DMD offered by vendors would be adopted if the information disseminated is reliable, and assist crucial enquiry important to customers. This was primarily mentioned across cases:

"[-] is the technology going to be fast at all times? [-] for me as a manager, speed and consistency is a determinant factor" (M15).

The DMD must be one capable of improving our process and delivery (M12). 
Several studies (Xu et al., 2007; TAL, 2018; Samad et al., 2018; Prause, 2019) have found that service delivery is a major element of any successful business. The quality of services rendered by new technology such as the creation of new or improve customers' benefits and enable efficient service delivery to move potential customers to actual adopters (Eze et al., 2018).

Customer fulfilment. Customer fulfilment is the capability of the DMD to render services aimed at satisfying the firms' clients since clients majorly rely on DMD for the purchase of the new product and payment for such product or services (Moon, 2003). The analysis revealed that customers were involved in DMD adoption decision because they often determine firms survival. This was echoed across cases and further supported by participant [A14]:

"Our customers are the reasons why we are still in business customers. Therefore, the DMD must be capable of satisfying the needs and desires of our customer" (M11).

"DMD helps to relate to our customers, without it it will be difficult to relate with customers and meet their desires [-]" M12.

This is consistent with Moon (2003) that found that when technology plays an essential role in the buying decision process, their performance is critical to business success (Eze and ChineduEze, 2018a, 2018b; Gbadegeshin et al., 2019). The implication of this is that SME managers are willing to adopt DMD if it would help them acquire new ones and retain the existing ones.

Intense competition. Competition is forces that compel the stability of a business. According to managers'strong competition influences DMD adoption success. This was echoed across cases:

"Because we are small and we want to remain in business, we must compete by getting an application that can help up fight competition" (M5).

"Because of the intense competition going on, I was concerned that we might be left behind" (M1).

"One thing that made us competitive, is because we often adopt new IT" (M9).

Khoumbati et al. (2006) similarly argue that competition is a significant determinants technology adoption by microbusinesses. DMD was both considered small business managers as a strategy that may improve the marketshare, promote businessactivities and remain competitive (Zhu et al., 2003; Zafar and Mustafa, 2017; Rahayu and Day, 2017; Gbadegeshin et al., 2019). The implication is that value SME managers attach to DMD is to be able to fight competition which is consistent with Salmela and Turunen (2003)' study.

\section{Impact expectancy}

Budget. Budget is linked to how effective the DMD would be in providing services with another expensive application offer as well as helping the firms' business processes without having to pay much. Micro-businesses are often deprived because they often lack resources to maintain their businesses; hence, they would prefer to minimise cost and improve profit margin continually. Therefore, the impact most micro-businesses anticipate from DMD is its ability to reduce cost. This was reverberated by managers: [M2], [M4], [M6], [M10], [M11], and [M23], and further supported:

\footnotetext{
"At the moment we are small. If it is relatively cheap and
} can accommodate our budget we are good to try it" (M1).
"[-] Budget is one of the key success factors we consider [-]. Can the application help reduce our budget in terms of cost and workforce?" (M15).

"We take both thneed and budget into consideration" (A20).

Consistent with the finding, Pirich et al. (2001) note that choice of micro-business managers to embrace any new technology dependent on the cost as well as the benefit and help in the longterm benefit of the firm (Lacovou and Dexter, 1995; Ramayah et al., 2016). The finding implies that if the budget associated with DMD is believed to be high, such technology may not be considered (Madukua et al., 2016; Khoumbati et al., 2006; Eze and Chinedu-Eze, 2018a; PR Newswire, 2019).

Business expansion. Technology advances productivity and helps small business in conducting their business activities and develop new industries. SMEs would experience improvement in business performance for those with specific growth objectives (Locke, 2004; Eze et al., 2014, 2018; McGrath and Maiye, 2010; Zafar and Mustafa, 2017). Business expansion is associated with the strength of the employees and market share tied to the IT devices. From the analysis, it was revealed that micro-businesses might be slow in engagingin DMD. However, such application must guarantee high performance as this can only be achieved through expansion:

"Our motivates to look for new DMDs is growth. How regular can the technology assist in increasing our customer base?" (M14).

"Can we acquire 45 clients or more in less than three months? That alone will be a deciding factor" (M5).

"If the DMD is good for the business's growth and expansion it will be tried" (A9).

The finding suggests that managers see business expansionas values the technology can bring to the business such as an increase in market share, sales volume as well as the extent to which customer is acquired and retained.

Diversity. Technology diversity is the capacity of the DMD to create unique services at all times or a niche that competitors may not be able to cope with, which may increase the chances of acquiring new clients. In the cause of the analysis, it was revealed that managers of micro-businesses might adopt DMD because of fair of being left behind. Hence, technology diversity was seen as a crucial influential factor, as noted across cases:

"for us to decide on that will depend largely on cost reduction of the application as well as assisting us in creating a niche in the market" (M5).

The DMDs should be able to differentiate us from our rivalry? (M13) by helping us to create something new at all times.

"We often consider special attributes of the technology and what it can bring to the business." A16

The finding is similar to previous studies (Lip-Sam and HockEam, 2011; Ramayah et al., 2016; Brown and Lockett, 2004; Yunis et al., 2017; Gbadegeshin et al., 2019). The finding implies that the diversity of any DMD is often linked to the capacity of the devices to distinguish a business from competitors. 
Return on investment. Return on investment is linked to the profits that DMD are capable of generating. It includes but not limited to market values and future abnormal returns by a business (Henderson et al., 2010; Eze et al., 2012). It was revealed that the majority of privately owned are profit-oriented, and businesses fail to generate a return on investments and increases in market shares which may windup in no distant time. This was supported supported: [M2], [M5], [M12], [M13] and M14,

"[-] We would always consider DMDs that can help us maximise profit" (M20).

“If we invest \#30,000, can it yield \#15,000?" (M23).

"We are after satisfying our clients as well as profit-making. If we are not doing that, we will short the company down" (A9).

The implication of this is that return on investment triggers investment in technology (Lim et al., 2011; Cavusoglu et al., 2004; TAL, 2018; Zafar and Mustafa, 2017; Rahayu and Day, 2017; Gbadegeshin et al., 2019; Teo et al., 2011). Hence, profit means that the organisation is satisfying its customers because the DMD adopted renders services that meet customers' demands.

\section{Conclusions}

First, the study explored the critical success factors shaping the adoption of DMD by micro-businesses. The study revealed 14 critical success factors that impact on the adoption of DMD. These factors have aided in developing a conceptual framework aimed at assisting micro-businesses in understanding better factors that may trigger the adoption of DMD in their business. The TOE framework was adopted and based on the elements of the TOE framework, the factors identified in this study were both theoretically and empirically classified. Functional capability, adaptive capacity and expandability are related to technology context. Collective understanding, degree of partnership and diversity of information are linked to the organisation while the level of training, quality of service delivery, customer fulfilment and intense competition are associated with organisation context.On the other hand, budget, business expansion, diversity and return on investment are linked to impact expectancy which was empirically derived. Although these factors shape the adoption of DMD, however, the extent to which they shape adoption varies considerably based on the total number of supporting evidence and supporting cases.

Second, since most conventional theories used to study IT adoption are narrowly minded (Gilmore et al., 2007; Xu et al., 2007; Eze and Chinedu-Eze, 2018a) and no single theory reasonably describes SMEs IT adoption behaviour because they either ignore some vital aspects of small business characteristics or are not designed bearing SMEs in mind (Dwivedi et al., 2009; Rantapuska and Ihanaine, 2008). The study has extended the TOE framework by incorporating an additional element and the associated factors which are not part of the primary elements of TOE frameworks. The element and the associated factors assisted in the extension of the TOE framework which has enriched the existing variables of the TOE framework. The extended TOE framework developed in this study can explain intra-firms' innovation adoption better (Oliveira and Martins, 2011; Madukuet et al., 2016), appears to be more robust and considers most SME adoption behaviour by drawing on a large number of variables and provide very significant analytical scope of DMD adoption (Oliveira and Martins, 2011) in Nigeria.

Third, few scholarly inquiries have focused on the adoption of DMD by micro-businesses in Nigeria, whereas the way DMD have been studied in Nigeria is by extrapolating knowledge put forth by foreigners (see Kannabiran and Dharmalingam, 2012; Tornatzky and Fleischer, 1990; Thong et al., 2020) as if Nigeria operates in the same kind of culture, level of socio and economic activities. Since there is still a dearth of local scholarship that provides a clear direction to this kind of research in remote areas in Nigeria, this study bridges the gap by exploring and developing a framework that gives a clear direction to this kind of study and rooted in developing context. This may aid future and contemporary researches in this part of the world.

Fourth, because the contemporary business environment is becoming challenges day after day, micro-businesses have constantly deliberated on the approach to use in adopting DMD constantly in a bid to gain new and broader insights on how best the devices can be deployed over time. However, the complex nature of these problems are becoming even more and more challenging for SMEs and this study especially if the framework is vital for practitioners that are involved in decision-making and seek to develop models for IT application (Derick and West, 2003). Therefore, the framework could be useful to micro-businesses in having a more indepth insight on the factors shaping DMD as well as a strong justification for the courses of action (Benbasat and Moore, 1992) in DMD adoption process. The practical insight can be utilised by SMEs to create awareness on the use of DMD and how to successfully adopt the new devices and avert some of the challenges they may be encountering in the future.

Limitations and future research. The paper is not without its limitations. One of the limtations of the study is because of the qualitative methodologies employed such as the research design, rigour in data collection and the management of huge volume of the raw data, analysis as well as the credibility of the findings. This may lead to unforeseen respondent and research bias in the data analysis which may lead to limited understanding of alternatives and insights into the factors influencing the adoption of DMD. Hence, other measures or methods ranging from case study to mix-method can be used to further validate the findings.

Secondly, in qualitative study, the number of respondents interviewed is usually small, and because the researcher interviewed a relatively small number of respondents ( 26 persons), it may be difficult to genaralise the finding and the framework. Therefore, more researchers should deploy alternative approach such ass confirmatory statistical techniques to test and ascertain the validity and reliability of the framework across a broader population and use it as a benchmark for DMD adoption study.

Finally, although the framework may not be applicable to other developing countries because of differences in the level of use of these devices, culture, social, and economic dimensions, more studies are required in other developing countries drawing on this framework. However, efforts should be made to incorporate other factors that may shape the adoption of DMD to see if this framework or an extended one can be generalised across other developing countries.

\section{Data avaliablity}

The data is not available for deposit due to confidentiality issues.

Received: 9 December 2019; Accepted: 24 July 2020;

Published online: 09 September 2020

\section{References}

Aboelmaged MG (2010) Predicting e-procurement adoption in a developing country. Ind Manag Data Syst 110(3):392-41 
Aduwa- Ogiegben SE, Iyamu EOS (2005) Using information and communication technology in secondary school in Nigeria: problems and prospects. Educ Technol Soc 8(1):104-112

Agarwel R (ed) (2000) Individual acceptance of information technologies. In: Framing the domains of letting management: projecting the future through the past. Pinnacle Education Resources, Cincinnati, pp. 85-104

Agostini L, Nosella A (2020) The adoption of Industry 4.0 technologies in SMEs: results of an international study. Manag Decision 58(4):625-643

Alba M, Diez L, Olmos E, Rodriguez R (2005) Global performance management for SMEs. International Federation for Information Processing book series. Springer, Boston

Alshamaila Y, Papagiannidis S, Li F (2013) Cloud computing adoption by SMEs in the northeast of England: a multi-perspective framework. J Enterp Inf Manag 26(3):250-275

Amirkhanpour M, Vrontis D, Thrassou A (2014) Mobile marketing: a contemporary. Strateg Perspect 9(3):252-269

Arghya R, Pradip KB, Shilpee AD (2020) Psychological analytics based technology adoption model for effective educational marketing in digital and social media marketing, emerging applications and theoretical development. Springer, Switzerland AG, 2020

Armstrong C, Sambamurthy V (1991) Technology assimilation in firms: the influence of senior leadership and IT infrastructures. Inf Syst Res 17(1):99-120

Asongu SA, Le Roux S (2017) Enhancing ICT for inclusive human development in sub-Saharan Africa. Technol Forecast Soc Change 118:44-54

Barrett M, Grant D, Wailes N (2006) ICT and organisation change: introduction to a special issue. J Appl Behav Sci 42(1):6-22

Benamati JS, Lederer AL (2001) Rapid information technology,coping mechanism and the emerging technology group. J Manag Info Syst 17(4):183-202

Benbasat I, Moore G (1992) Development of measures for studying emerging technologies. Proceedings of the Twenty-fifth Hawaii Internationalconference on system sciences, Kauai, HI, USA. 7th-10th January, 1992. https://doi.org/ 10.1109/HICSS.1992.183351

Benbasat I, Goldstein DK, Mead M (1987) The case research strategy in studies of information systems. MIS Q 11(3):369-386

Boyatzis R (1998) Transforming qualitative information: thematic analysis and code development. Sage Publication Ltd, London

Brown DH, Lockett N (2004) Potential of critical e-applications for engaging SMEs in e-business: a provider perspective. Eur J Inf Syst 13:21-34

Bryman A (2008) Social research methods. Oxford University Press, Oxford

Cavusoglu H, Mishra B, Raghunathan S (2004) A model for evaluating IT security investment. Commun ACM 47(7):87-92

Ciechanowski L, Przegalinska A, Magnuski M, Gloor P (2019) In the shades of the Uncanny Valley: an experimental study of human-chatbot interaction. Futur Gener Comput Syst 92:539-548

Dedrick J, West J (2003) Perceived usefulness, perceived ease of use, and user acceptance of information technology. MIS Q 13(3):319-339

De Haan E, Kannan PK, Verhoef PC, Wiesel T (2018) Device switching in online purchasing: examining the strategic contingencies. J Market 82(5):1-19

DePietro R, Wiarda E, Fleischer M (eds) (1990) The context for change: organization, technology and environment. In: Tornatzky LG, Fleischer M (eds) The processes of technological innovation. Lexington Books, Lexington, pp. 151-175

De Saulles M (2007) Information literacy amongst UK SMEs: an information policy gap. Aslib Proc 51(1):68-79

Dubé JP, Fang Z, Fong N, Luo X (2017) Competitive price targeting smartphone coupons. Market Sci 36(6):944-975

Dwivedi YK, Papazafeiropoulo A, Chuang TT, Nakatani K, Zhou D (2009) An exploratory study of the extent of information technology adoption in SMEs: an application of upper echelon theory. J Enterprise Inf Manag 22(1-2):183-196

Economides N, Jeziorski P (2017) Mobile money in Tanzania. Market Sci 36 (6):815-837

Elliot S, Loebbecke C (2000) Interactive,inter-organisational innovation in electronic commerce. Inf Technol People 13(1):46-66

Eze SC, Chinedu-Eze CV (2018a) Examining information and communication technology (ICT) adoption in SMEs: a dynamic capabilities approach. J Enterprise Inf Manag 31(2):338-356

Eze SC, Chinedu-Eze VC, Bello AO, Inegbedion H, Nwanji T, Asamu F (2019) Mobile marketing technology adoption in service SMEs: a multi-perspective framework. J Sci Technol Policy Manag. https://doi.org/10.1108/JSTPM-112018-0105

Eze S, Duan Y, Chen H (2012) Factors affecting emerging ICT adoption in SMEs: An Actor Network Theory Analysis. International Conference on EbusinessTechnology \& Strategy (ICETS). Tanjin, China

Eze S, Duan Y, Chin H (2014) Examining emerging ICT's adoption in SMEs from a dynamic process approach. Inf Technol People 27(1):63-82

Eze SC, Chinedu-Eze VC, Bello AO (2018) Actors and emerging information, communications and technology (EICT) adoption: a study of UK small and medium services enterprises'. Cogent Bus Manag 5(1):1-19
Eze SC, Chinedu-Eze VC (2018b) Strategic roles of actors in emerging information communication technology (EICT) adoption in SMEs: actor-network theory analysis. Bottom Line 31(2):114-136

Fitzgerald B, Kenny T (eds) (2003) Open-source software in the trenches: lessons from large-scale implementation. In: March ST, Massey A, DeGross JI (eds) Proceeding of the 24th International Conference on Information Systems (ICIS, 2003). The Association for Information Systems, Seattle, WA, pp. 316-326

Franco M, Garcia M (2018) Drivers of ICT acceptance and Implementation in micro-firms in the estate agent sector: influence on organizational performance. Inf Technol Dev 24(4):658-680

Gangwar H, Date H, Ramaswamy R (2015) Understanding determinants of cloud computing adoption using an integrated TAM-TOE model. J Enterprise Inf Manag 28:107-130

Gbadegeshin SA, Solomon SO, Sunday AO, Ismaila TS, Dandison CU, Olayemi O, Ayobami A (2019) Application of information and communication technology for internalization of Nigerian small and medium enterprises. Electric J Inf Syst Dev Ctries 8(1). https://doi.org/10.1002/isd2.12059

Gbandi EC, Amissah G (2014) Financing options for small and medium enterprises (SMEs) in Nigeria. Eur Sci J 10(1):327-340

Gholami B, Kaviani F, Zabihi E (2009) Web 2.0, a boost in IT infrastructure flexibility and team collaboration. Second International conference on computer and electrical engineering. IEEE Computer Society, United Arab Emirates

Gilmore A, Carson D (eds) (2007) Teaching and research in small business enterprise marketing: a critique and some alternatives. In: Hine D, Carson (eds) Innovative methodologies in enterprise research. Edward Elger, Cheltenham

Gutierrez A, Boukrami E, Lumsden R (2015) Technological, organisational and environmental factors are influencing managers' decision to adopt cloud computing in the UK. J Enterprise Inf Manag 28(6):788-807

Henderson CE, Dakof GA, Greenbaum PE, Liddle HA (2010) Effectiveness of multidimensional Family Therapy with Higher Severity Substance-abusing adolescents: Report from two randomized controlled trials. J Consult Clin Psychol. https://doi.org/10.1037/a0020620

Hong H, Hammad AWA, Sepasgozar S, Akbarnezhad A (2018) BIM adoption model for small and medium construction organisations in Australia. Eng Constr Archit Manag. https://doi.org/10.1108/ECAM-04-2017-0064

Hong W, Thong JL, Chasalow LC, Dhillon G (2011) User acceptance of agile information systems: a model and empirical test. J Manag Inf Syst 28 (1):235-275

Hopkins J, Turner J (2012) Go mobile: location-based marketing, apps, mobileoptimised ad campaigns, 2D codes and other mobile strategies to grow your business. Wiley, Hoboken

Hosseini MR, Banihashemi S, Chileshe N, Namzadi MO, Udeaja C, Rameezdeen R, McCuen T (2016) BIMadoption within Australian Small and Medium-sized Enterprises (SMEs): an innovation diffusion model. Constr Econ Build 16 (3):71-86. https://doi.org/10.5130/AJCEB.v16i3.5159

Jones P, Simmons G, Packham G, Beynon-Davies P, Pickernell D (2014) An exploration of the attitudes and strategic responses of sole-proprietor microenterprises in adopting ICT. Int Small Bus J 32(3):285-306

Kale Y (2017) Report on National Survey of Micro, Small, and Medium Enterprises (MSME). National Bureau of Statistics, Lagos state, Nigeria

Kannabiran G, Dharmalingam P (2012) Enablers and inhibitors of advanced information technologies adoption by SMEs: an empirical study of Auto Ancillaries in India J Enterprise Inf Manag 25(2):186-209

Khoumbati K, Themistocleous M, Irani Z (2006) Evaluating the adoption of enterprise application integration in health- care organisation. J Manag Inf Syst 22(4):69-108

Lacovou ALIIB, Dexter A (1995) Electronic data interchange and small organisations: adoption and impact of technology. MIS Q 19(4):465-485

Lee Y (2003) The technology acceptance model: past, present and future. Commun Assoc Inf Syst 12(50):752-780

Lee J (2004) Discriminant analysis of technology adoption behaviour: a case of internet technologies in small business. J Comput Inf Syst 44(4):57-66

Leppäniem M, Karjaluoto H, Salo J (2004) The success factors of the mobile advertising value chain. E-Bus Rev 4:93-97

Li X, Troutt MD, Brandyberry A, Wang T (2011) Decision factors for the adoption and continued use of online direct sales channels among SMEs. J Assoc Inf Syst 12(1):1-31

Lian JW, Yen DC, Wang YT (2014) An exploratory study to understand theoretical factors affecting the decision to adopt cloud computing in Taiwan hospital. Int J Inf Manag 34(1):28-36

Lim JE, Dehning B, Richardson VJ, Smith RE (2011) A meta-analysis of the effects of IT investment on firm financial performance. J Inf Syst 25(2):145-169

Lip-Sam T, Hock-Eam L (2011) Estimating the determinants of B2Be-commerce adoption among small \& medium enterprises. Int J Bus Soc 12(1):15-30

Locke S (2004) ICT adoption and SME growth in New Zealand. J Am Acad Bus 3 (13):93-102 
Macredie RD, Mijinyawa K (2011) A theory-grounded framework of open-source software adoption in SMEs. Eur J Inf Syst 20:237-250

Madukua DK, Mpinganjirab M, Duhca H (2016) Understanding mobile marketing adoption intention by South African SMEs: a multi-perspective framework. Int J Inf Manag 36:711-723

MacLennan L, Van Belle P (2014) Factors affecting organisational adoption of service-oriented architecture (SOA). Inf Syst E-bus Manag 12:71-100

McGrath K, Maiye A (2010) The role of institution in ICT innovation: learning from innervations in Nigeria-government initiatives. Inf Technol Dev 16(4):260-278

Martin L, Matlay H (2001) Blanket approaches to promoting ICT in small firms: some lessons from the IDT ladder adoption model in the UK. Internet Res Electron Netw Appl Policy 11(5):399-410

Mason J (1996) Qualitative resarching. Sage Publication, London

Miles MB, Huberman AM (1994) Qualitative data analysis: an expanded sourcebook. Sage Publication Ltd, Thousand Oaks

Moon Y (2003) Don't blame the computer when self-disclosure moderates the selfserving bias. J Consum Psychol 13(1-2):125-137

Mutula SM, Brakel PV (2006) E-readiness of SMEs in the ICT sector in Botswana concerning information access. Electron Libr 24(3):402-417

Myers MD (1997) Qualitative research in information systems. MIS Q 21(2):241-242

Napitupulu D, Syafrullah M, Rahim R, Abdullah D, Setiawan MI (2018) Analysis of userreadiness toward ICT usage at small medium enterprise in South tangerang. J Phys: Conf Ser 1007(1). https://doi.org/10.1088/1742-6596/1007/1/012042

Nelson KM, Cooprider JG (1996) The contribution of shared knowledge to IS group performance. MIS Q 20(4):409-429

Newswire PR (2019) Global social media analytics industry, forecast to 2024-high adoption rate of social media analytics solutions SMEs. Reg Bus News. https://www.reportlinker.com/p05073747/?utm_source=PRN

Nuryyev G, Wang Y-P, Achyldurdyyeva J, Jaw B-S, Yeh Y-S, Lin H-T, Wu L-F (2020) Blockchain technology adoption behavior and sustainability of the business in tourism and hospitality SMEs: an empirical study. Sustainability 12(3):1256. https://doi.org/10.3390/su12031256

Oates BJ (2006) Researching information systems and computing. SAGE Publication Inc, London

Okundaye K, Fan Susan K, Dwyer Rocky J (2019) Impact of information and communication technology in Nigeria small to medium-sized enterprices. J Econ Financ Adm Sci 24(47):9-46. https://doi.org/10.1108/JEFAS-08-2018-0086.

Oliveira T, Martins MF (2011) Literature review of information technology adoption models at the firm level. Electron J Inf Syst Eval 14:110-121

Ongori H, Migiro SO (2010) Information and communication technology adoption: literature review. J Chin Entrep 2(1):93-100

Parellada FS, Sorian DS (2011) An overview of the service industries future priorities: Linking past and future. Ser Ind J 31(1):1-6

Persaud A, Azhar I (2012) Innovative mobile marketing via smartphones: are consumers ready?. Market Intell Plan 30(4):418-443. https://doi.org/10.1108/ 02634501211231883

Pirich A (2001) An Interface between entrepreneurship and innovation: New Zealand SMEs perspective. Paper prepared for the 2001 DRUID Conference, Aalborg, Denmark

Prause M (2019) Challenges of industry 4.0 technology adoption for SMEs: the case of Japan. Sustainability 11(20):5807

Rahayu R, Day J (2017) E-commerce adoption by SMEs in developing countries: evidence from Indonesia. Eurasian Bus Rev 7(1):25-41

Ramayah T, Ling NS, Taghizadeh SK, Rahman SA (2016) Factors influencing SMEs website continuance intention in Malaysia. Telemat Inform 33(1):150

Rantapuska T, Ihanainen O (2008) Knowledge use in ICT investment decision making of SMEs. J Enterprise Inf Manag 21(6):585-596

Raymond L, Bergeron F (2008) Enabling the business strategy of SMEs through EBusiness capabilities: a strategic alignment perspective. Ind Manag Data Systs 108(5):577-595

Ritchies B, Brindley C (2005) ICT adoption by SMEs: implication for relationships and management. New Technol Work Employ 20(3):205-217

Reich BH, Benbasat I (2000) Factors that influence the social dimension of alignment between business and information technology objectives. MIS Q 24(1):81-111

Ruivo P, Oliveira T, Neto M (2014) Examine ERP post-implementation stages of use and value: empirical evidence from Portuguese SMEs. Int J Account Inf Syst 15(2):166-184

Salmela H (2003) Competitive implications of information technology in the public sector: the case of a city geographic information system. Int J Public Sector Manag 16(1):8-26. https://doi.org/10.1108/09513550310456391

Samad MES, Steven RD, Martin L (2018) Dissemination practices of construction sites' technology vendors in technology exhibitions. J Manag Eng 34(6). https://doi.org/10.1061/\%28ASCE\%29ME.1943-5479.0000650

Samoilenko S, Osei-Bryson K-M (2018) An analytical framework for exploring context-specific micro-economic impacts of ICT capabilities Inf Technol Dev 24(4):633-657
Scharl A, Dickinger A, Murphy J (2005) Diffusion and success factors of mobile marketing. Electron Commer Resource Appl 4:159-173

Schwarz A, Chin W (2007) Looking forward: toward an understanding of the nature and definition of IT acceptance. J Assoc Inf Syst 8(4):230-243

Shankar V, Balasubramanian S (2009) Mobile marketing: a synthesis and prognosis. J Interact Market 23(2):118-129

Shankar V, Venkatesh A, Hofacker C, Naik P (2010) Mobile marketing in the retailing environment: current insight and future research avenue. J Interact Market 24:111-120

Silva L (2007) Post-positivist review of technology acceptance model. J Assoc Inf Syst 8(4):255-266

Smutkupt P, Krairit D, Esichaikul V (2010) Mobile Marketing: Implications for Marketing Strategies. Int J Mob Mark 5(2):126-139

Small and Medium Enterprise Development of Nigeria and National Bureau of Statistics collaborative Survey (2013). https://www.smedan.gov.ng/images/ PDF/2013-MSME-Survey-Summary-Report.pdf

TAL Ariana-Emanuela (2018) The benefits of social media adoption in a SME. A competitive advantage Perspective. Econ Stud 25:215-221

Teo THS, Srivastava SC, Ranganathan C, Loo JWK (2011) A framework for stakeholder-oriented mindfulness: case of RFID implementation at $\mathrm{YCH}$ Group, Singapore. Eur J Inf Syst 20:201-220

Tenkasi RV, Richard BJ (1995). Perspective Making and Communities of knowing. J Org Sci https://doi.org/10.1287/orsc.6.4.350

Teo SY, Pan SL (2008) Understanding the influence of social integration in enterprise systems use. J Enterprise Inf Manag 21(5):493-511

Tobora OO (2014) Challenges faced by entrepreneurs and the performance of small and medium scale enterprises (SMEs) in Nigeria: an intellectual Capital issue. Int Lett Soc Humanist Sci 42:32-40

Tob-Ogu A, Kumar N, Cullen J (2018) ICT adoption in road freight transport in Nigeria - a case study of the petroleum downstream sector. Technol Forecast Soc Change 131:240-252. https://doi.org/10.1016/j.techfore.2017.09.021

Thong S, Luo X, Xu B (2020) Personalized mobile marketing strategies. J Acad Market Sci 48:64-78

Tornatzky L, Fleischer M (1990) The process of technology innovation. Lexington Books, Lexington

Ukoha O, Awa H, Nwuche C, Asiegbu I (2011) Analysis of explanatory and predictive architectures and the relevance in explaining the adoption of IT in SMEs. Interdisplin J Inf Knowl Manag 6:216-229

Wamba SF, Carter L (2014) Social media tools adoption and use by SMEs: An empirical Study. J Organ End User Comput 26(2):1-17. https://doi.org/ 10.4018/joeuc.2014040101

Williams M, Dwivedi YK, Lal B, Schwarz A (2009) Contemporary trends and issues in IT adoption and diffusion research. J Inf Technol 24:1-10

Wonglimpiyarat (2015) Challenges of SMEs innovation and entrepreneurial financing. World J Entrep Manag Sustain Dev 7(4):295-311

Xu M, Rohatgi R, Duan Y (2007) E-business adoption in SMEs: some preliminary findings from electronic component industry. Int J E-Bus Res 3(1):74-90

Yesbank (2009) Technology for financial efficiency, vol. 1(1). YES BANK's Knowledge Banking Publication

Yunis M, El-Kassar A, Tarhini A (2017) Impact of ICT-based innovations on organizational performance: the role of corporate entrepreneurship. J Enterp Inf Manag 30(1):122-141. https://doi.org/10.1108/JEIM-01-2016-0040

Zafar A, Mustafa S (2017) SMEs and its role in economic and socio-economic development of Pakistan. Int J Acad Res Account Fin Manag Sci 7 (4):195-205

Zhu K, Kraemer K, Xu S (2003) Electronic business adoption by Europe firms: a cross-country assessment of the facilitators and inhibitors. Eur J Inf syst 12 (4):251-256

\section{Author contributions}

All the authors greatly contributed in designing, analysis, or interpretation. They were also involved in drafting, revising the paper. Collectively they agreed on the final version to be published and agreed to be accountable for all the aspects of the work.

\section{Competing interests}

The authors declare no competing interest.

\section{Additional information}

Correspondence and requests for materials should be addressed to S.C.E.

Reprints and permission information is available at http://www.nature.com/reprints

Publisher's note Springer Nature remains neutral with regard to jurisdictional claims in published maps and institutional affiliations. 
(c) (i) Open Access This article is licensed under a Creative Commons Attribution 4.0 International License, which permits use, sharing, adaptation, distribution and reproduction in any medium or format, as long as you give appropriate credit to the original author(s) and the source, provide a link to the Creative Commons license, and indicate if changes were made. The images or other third party material in this article are included in the article's Creative Commons license, unless indicated otherwise in a credit line to the material. If material is not included in the article's Creative Commons license and your intended use is not permitted by statutory regulation or exceeds the permitted use, you will need to obtain permission directly from the copyright holder. To view a copy of this license, visit http://creativecommons.org/ licenses/by/4.0/.

(C) The Author(s) 2020 